\title{
Polska literatura najnowsza w świetle reinterpretacji założeń polifonicznej teorii literatury Michała Bachtina: próba rozpoznania na przykładzie analizy powieści Prymityw Marcina Kołodziejczyka
}

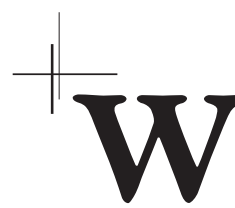

prowadzenie

W rozprawie Problemy poetyki Dostojewskiego Michał Bachtin pisze: „Żyję w świecie cudzych słów. Całe moje życie polega na orientowaniu się pośród nich, reagowaniu na nie”. Rosyjski uczony zapoczątkował tym samym nowy wymiar postrzegania teorii powieści, której clou zawiera się w polifoniczności i w koncepcji „cudzego słowa”. Teoria ta, wielokrotnie wykorzystywana i przystosowywana przez literaturoznawców do przystających im warunków i czasów, okazuje się jednak ciągle żywotna.

"Cudze słowa” zmuszają wszak do nieustannego interpretowania i negocjowania znaczeń, które w rezultacie doprowadzają do ukonstytuowania się własnej tożsamości. Wydaje się, że badacze literatury są przyzwyczajeni do owej wielogłosowości kultury. Najpierw post-strukturalizm, szczególnie kierunek dekonstruktywistyczny, utwierdził w przekonaniu, że poznanie empiryczne bywa zwodnicze, zaś interpretacje mogą — a nawet muszą - być wielogłosowe i uwikłane w kontekst społeczno-kulturowy, bo prawdą rządzą - idąc tropem Fryderyka Nietzschego - ulokowane pomiędzy językową precyzją a ruchliwą armią metafor, metonimii i antropomorfizmów prawidła (Nietzsche 1993: 188-189).

Następnie zmieniająca się sytuacja geopolityczna zmusiła uczonych i autorów do otwarcia się na nowe kultury oraz do zaakceptowania faktu ich przemieszania się. Z jednej więc strony kulturowe teorie literatury skierowane w stronę podejścia hermeneutyczno-fenomenologicznego w naukowcach pobudzają stan permanentnego zdezorientowania poznawczego, z drugiej zaś - otwierają na wielogłosowość narracji, zatem na zapoznanie się „z tak wielką 
różnorodnością istot ludzkich, jak to tylko możliwe” (Rorty 2003: 115). Jeśli zatem najnowsza literatura jest naznaczona doświadczeniem przemian paradygmatów funkcjonowania jednostki w świecie „małych kultur”, to trzeba zastanowić się, w jaki sposób można odczytać paradygmaty kulturowe w niej zakodowane. Te gwałtowne przeobrażenia, nastawione raczej na ilość komunikatów poznawczych, niż na ich jakość, wybijają wszak z rytmu kulturowego i wprowadzają w stany szoku i szarpaniny emocjonalnej, dyktowane przez brak poczucia przynależności do konkretnego tu, ale też zmuszają do przekonstruowania pewnych, do tej pory stałych, wzorów funkcjonowania. I to właśnie ilościowa orientacja kulturowa, swoista jej wielogłosowość, wydaje się określać estetyczne i ideologiczne wymiary najnowszej polskiej literatury.

Heteroglosja, zawierająca się tout court w stwierdzeniu, że jest to zjawisko występowania w tekście lub w mowie dwóch lub więcej rodzajów języka (CALD), rozwinięta przez Michaiła Bachtina w kulturowym znaczeniu, wydaje się odpowiadać potrzebom opisania powieści najnowszych. Powrót do teoretycznego i praktycznego rozpoznania rosyjskiego uczonego gwarantuje bowiem możliwość wykroczenia poza czysto językoznawcze traktowanie i zaadaptowanie do interkulturowej teorii literatury zjawiska szerokorozumianej wielogłosowości. Pisma uczonego to wszak wciąż aktualny zbiór wskazówek dla badań zorientowanych wobec prymatu kontekstu nad znaczeniem tekstowym (Park-Fuller 1986: 1), bo teoria dialogiczności opiera się właśnie na przekonaniu, że każda wypowiedź językowa bezspornie łączy się z ideologią.

Jak zatem czytać najnowszą polską literaturę? Czy można ją opisywać inaczej niż przez pryzmat metamorfozy cywilizacyjnej, jaka dotknęła także Polskę w ostatnich latach? Co Bachtinowska polifonia i „cudze słowo” mogłyby nam powiedzieć o sposobach radzenia sobie jednostek z szokiem poznawczym, jaki budzi gwałtowne odejście od kształtowanych przez setki lat kulturowych ram zachowań społecznych? Jakie wnioski z obserwacji językowych (także artystycznych) sposobów artykułowania emocji uwarunkowanych kulturowo można wyciągnąć? Jak Ja konstytuuje się wobec $M y$ („małej kultury”)? I wreszcie, jak traktować samą heteroglosję we współczesnych badaniach literackich: jako Bachtinowską polifoniczność czy jako wyróżnik ideologiczny i tematyczny? A może coś pomiędzy tymi dwoma postulatami?

\section{Wielogłosowa kultura: próba nakreślenia definicji}

Wobec tak zarysowanego problemu najpierw warto zastanowić się, jak powinniśmy definiować kulturę. Przyjęcie heteroglosji jako wyznacznika estetycznego i ideologicznego polskiej literatury najnowszej implikuje bowiem konieczność przyjęcia takiej definicji kultury, która wskazywałaby już nie tylko na duchowe i materialne dziedzictwo jakiegoś społeczeństwa, na przykład polskiego, lecz także na współistnienie różnorodnych komponentów wzajemnie się określających, a czasem nawet wykluczających. Kulturę należy zatem potraktować jako wypadkową wielu różnych praktyk, często zajmujących tę samą przestrzeń, a także jako miejsce „pomiędzy”, będące zarazem harmonijnym iloczynem części na nowo skomponowanych. Claire Kramsch zamyka powyższe w konstatacji, że kultura to „symboliczne miejsce, które w żadnym wypadku nie jest jednolite, stabilne trwałe i jednorodne" [A symbolic place that is by no means unitary, stable, permanent and homogenous] (Kramsch 2009: 238). To rozpoznanie uzupełnia twierdzenie Homiego Bhabha, który zauważa, że „kultury nigdy nie są same w sobie jednolite, ani po porostu dualistyczne w relacjach na linii Swój - Obcy” 
[cultures are never unitary in themselves, nor simply dualistic in the relation of Self to Other] (Bhabha 1994: 52), bo w trakcie ich powstawania „rodzi się coś innego, coś nowego i nie do poznania, nowy obszar negocjowania znaczenia i reprezentacji" [gives rise to something different, something new and unrecognizable, a new area ofnegotiation of meaning and representation] (Bhabha 1990: 211).

Współczesna sytuacja kulturowa, bezspornie powiązana z przemianami gospodarczymi i politycznymi, zmusza do tego, by odejść od pojmowania człowieka jako jednojęzycznego narratora (monoglossic narrator), na rzecz dostrzeżenia w nim jednostki skupiającej w sobie wiele językowych sposobów reprezentacji znaczenia - czyli traktowania go jako narratora różnojęzycznego (heteroglossic narrators), ukształtowanego wskutek „budujących i szokujących, twórczych i będących powodem poważnych trudności" (Boski 2010: 11) doświadczeń międzykulturowych. Dostrzeżenie tej właściwości kultury pozwala zaś na to, by prawidłowo odczytać właściwości estetyczne dzieł zrodzonych w czasach dynamicznych zmian społecznych, politycznych, estetycznych oraz by wypracować system krytyczny przystający do tej nowej, często budzącej lęk, rzeczywistości. W dobie wzmożonych przemian trzeba bowiem nauczyć się wytwarzania nowych hipotez zrozumienia rzeczywistości językowo-kulturowej, które wpisują się, jak sądzę, nie tylko w „dyskursywne praktyki mówców i pisarzy żyjących w postkolonialnych czasach w złożonych społeczeństwach industrialnych" [discursive practices of speakers and writers living in post-colonial times in complex industrialized societies] (Kramsch 2009: 236), lecz także w estetyczne i krytyczne praktyki użytkowników języka i pisarzy żyjących w czasie intensyfikacji doświadczeń międzykulturowych w społeczeństwach dotąd monokulturowych. Kulturę, w obliczu silnych zmian cywilizacyjnych, należy więc zdefiniować jako zbiór różnorodnych elementów symbolicznych ze sobą wspólistniejących na jednym obszarze poznawczym, wzajemnie się uzupełniających i zarazem ze sobą rywalizujących, co zmusza jednostki do nieustannego wypracowywania systemu znaczeń oraz poszukiwania sposób ich artykulacji w ramach negocjacji kulturowych.

\section{Surrealistyczny karnawał zniekształconych głosów: Prymityw w świetle koncepcji Bachtina}

Heteroglosję, a więc różno- czy też wielogłosowość, można traktować na dwa sposoby, dające niewykluczające się, lecz uzupełniające diagnozy. Pierwszym z nich jest przyjęcie teorii polifoniczności powieści Bachtina oraz przyjrzenie się strukturze narracyjnej dzieła literackiego, drugim zaś - zinterpretowanie przy jej pomocy afektów społeczeństwa polskiego wobec zmiany kulturowej, niejako „przepisanych” na karty literatury w postaci języka artystycznego.

Nie ma chyba lepszego do analizy zorientowanej na sensu stricto polifoniczność materiału w najnowszej literaturze niż powieść Marcina Kołodziejczyka Prymityw. Wszystkie projekty Kołodziejczyka, czy to reporterskie, czy komiksowe i powieściowe, odznaczają się bowiem spójnością, za którą Edyta Żyrek-Horodyska uznaje transgatunkowość, stanowiącą o koherencji tematycznej i językowej dorobku autora (Żyrek-Horodyska 2019: 23). Krakowska badaczka stawia także tezę, iż jest to twórczość, która z uwagi na swoje bogactwo językowo-tematyczne, stanowi dogodny grunt dla komparatystyki mediów. W swojej eseistycznej próbie opisania powieści Prymityw chciałabym uzupełnić głos badaczki o interpretację skierowaną ku heteroglosji i implicytne w stosunku do niej uwikłania powieści w przemiany społeczno-polityczne zaklęte w tekście. Pokażę także, jak język artystyczny 
Prymitywa z jednej strony staje się reprezentacją stanów emocjonalnych charakterystycznych dla psychologicznego profilu polskiej tożsamości, a z drugiej strony, jak ów język w nią uderza i wielogłosowo ją rozbija.

Warto zauważyć, ze sam Kołodziejczyk swoją twórczość określa jako zjawisko „orkiestracji”, która jest rozpisana na wiele instrumentów ${ }^{1}$, tak więc wydaje się, że świadomie nawiązuje do Bachtinowskiej polifonii, dzięki czemu Prymityw, podobnie jak powieści Fiodora Dostojewskiego, rozbrzmiewa wieloma głosami, z których żaden nie dominuje i żaden nie jest porte parole autora. Kołodziejczyk konstruuje zatem opowieść na podstawie „cudzych słów”, czym wplata ją w ogniwo niekończącego się łańcucha komunikacyjnego, w którym pobrzmiewają wszystkie „historyczne” użycia słów. Oto bowiem tłem powieści Kołodziejczyka są zagadnienia społeczno-politycznie, niejako dookreślające czas i miejsce, które są także pretekstem do „przepisania” tego, co już zostało „wypowiedziane” i co pozwala na prezentację różnych modelów zachowań jednostek. Kołodziejczyk jasno przy tym wskazuje na konkretny czas:

A gdy się wypełniły dni i zbliżało się lato tego konkretnie 15 roku, w którym młody Bożydar Jałowy pokonał starego Darzbora Memłę, zdobywając tytuł prezydenta Polski - co w sumie nikogo u nas nie obeszło, bo niewielu się orientowało w perspektywach dla kraju, bo sami byliśmy w trudnym położeniu i mieliśmy ciężko $[\ldots]$.

(Kołodziejczyk 2018: 109)

oraz konkretne osoby, występujące na polskiej scenie politycznej:

W dobie historycznej lat dwutysięcznych-nastych Teść zagorzale sprzyjał partii Radosława Katyńskiego, dlatego że zaistniały w telewizji świat nie odpowiadał mu co do zasady; Teść gardził współczesnością, a współczesność traktowała go viceversa - był więc zdecydowanie przeciwny spadającym bez powodu samolotom, niepolskiej kuchni, międzymęskiemu uczuciu, ruskim, chinolom, niemiaszkom, targowicy, warchołom, kobietom niegotującym, uni jewriepejskiej

i joggingowi.

(Kołodziejczyk 2018: 122)

Premier Roland Błysk, widziany w przelocie w dużych pokojach, we wiadomościach, faktycznie jak dywan liniał i się plecami cofał na z góry upatrzone etaty

brukselskie.

(Kołodziejczyk 2018: 207)

1 Marcin Kotodziejczyk: ta książka w catości sktada się z podstuchanych rozmów, audycja „Wybieram Dwójkę” z 3.4.2018 r., www.polskieradio24.pl/76/196/Artykul/2083948\%2CMarcin-Kolodziejczyk-ta-ksiazka-wcalosci-sklada-sie-z-podsluchanych-rozmow. 
Tym samym konstrukcja Kołodziejczyka wpisuje się w ten aspekt zagadnienia heteroglosji, który dotyczy jej uwikłania w kontekst społeczno-polityczny, w owe „cudze słowa”, które nawarstwiają się w kolejnych przetworzeniach i obrazują stan świadomości, czy też reakcje jednostek na zmiany. Jednostkom niedojrzałym do tego, by zaakceptować zmieniającą się rzeczywistość, współczesność wadzi. Tymczasem — jak zauważa Paweł Boski - „coraz częstsze, chciane i niechciane kontakty z ludźmi pochodzącymi z odmiennych kultur są [...] dziś faktem, który wpływa na kształt naszego życia i nie można go ignorować” (Boski 2010: 11). I tu wplotę rozpoznanie Żyrek-Horodyskiej, które następnie spróbuję uzupełnić:

Można zatem dostrzec, że powieść otworzyła przed autorem nowe sposoby wyrazu; pozwoliła z większą swobodą odnieść się do aktualnych wydarzeń i rzeczywistych postaci, które w Prymitywie są przedstawiane, co prawda, w kostiumie stworzonym z przerysowanych masek i pseudonimów, z łatwością jednak mogą zostać zdemaskowane.

(Żyrek-Horodyska 2019: 35)

Konstrukcja Kołodziejczyka, oczywiście otwiera na nowe sposoby wyrazu, pozwala odnosić się do aktualnych wydarzeń i rzeczywistych postaci, jednak owo przerysowanie, kostiumy, maski, to także część surrealistycznego karnawału zniekształconych głosów, które prezentują sposoby radzenia sobie ze zmianami oraz strategie budowania językowych reprezentacji emocji. Narracja powieści Kołodziejczyka jest bowiem nie tylko zmianą punktu widzenia, który ma demaskować różne osoby czy zdarzenia lub ma być próbą prezentacji stanu polskiej sceny politycznej, lecz także jest rozwarstwieniem jednego głosu na kilka innych, co ma obrazować walkę z zagrożeniem, jakie w poczuciu jednostki przynosi odejście od zastanego paradygmatu kulturowego. Teść nie jest, jak się zdaje, jednostką gotową do zaakceptowania czegoś, co odbiega od zastanych paradygmatów, bo jest reprezentantem psychologicznego profilu kultury polskiej, którego podstawę stanowi nieufność wobec władzy, przy jednoczesnym identyfikowaniu się z symboliką narodową, niechęć wobec tych, którzy odnoszą sukces, niechęć do ugody oraz przyjęcie, że wszystko to, co nowe - „współczesne” — jest podejrzane (Boski 2010: 373-397). Kultura afirmacji, charakterystyczna dla retoryki nowoczesności, wadzi Teściowi, bo nie wpisuje się w kulturę narzekania, która dotyczy raczej spraw publicznych niż rodzinnych.

Zauważmy także, że narracja Prymitywa często wychodzi poza nią samą, to znaczy narrator bezpośrednio zwraca się do czytelnika. Kiedy więc narrator zachęca: „Teraz popatrzcie się na to [...]” (Kołodziejczyk 2018: 206) albo wychodzi z pytaniem: „Zastanawialiście się kiedyś, jak bardzo smutna jest Warszawa z punktu widzenia skuterowego dostawcy pizzy w deszczu?" (Kołodziejczyk 2018: 316), to tak naprawdę wzbudza podejrzliwość, wzmaga wielość punktów widzenia i pokazuje, że każdy jest społecznie i kulturowo odpowiedzialny i powinien z uwagą przyglądać się „cudzym słowom”. To nakładanie się na siebie głosów, specyficzne przemieszanie narracji literackiej i oralnej sytuuje wszak narratora nie w pozycji gawędziarza - lecz w pozycji dynamicznej siły jednoczącej i różnicującej interpretacje świata. Dla Żyrek-Horodyskiej to gest w stronę czytelnika, wciągnięcie go w powieściowy świat, jednak — jak sądzę — jest to także zacieranie różnic pomiędzy tym, co „moje”, a tym, co 
„cudze”, sui generis wskazówka jedności komunikacji w jej wielości. Przyjęcie takiej perspektywy narracyjnej, zgodnie z rozpoznaniem Bachtina, podważa bowiem, możliwości obiektywnego „przepisywania” treści rzeczywistych w tkankę języka i prowokuje do tego, by ciągle interpretować to, co powieść nam daje.

Ową jednoczącą siłę narracji doskonale zdaje się oddawać fragment powieści wyjaśniający przyczyny przemiany Ilony Żyły w Wiktorię Wiedeńską, czyli „miejskie” alter ego silnej i spełnionej kobiety, pragnącej ludzkich spojrzeń pełnych podziwu:

Teraz popatrzcie się na to: jedzie-jedzie Wiktoria Wiedeńska kolejką do Działdowa w poczuciu czempionatu nad ogólnopolskimi uwarunkowaniami — spektakularna (na filigranowego tygrysa), lekko wyniosła (w typie niekończącego się selfie), dobrze odżywiona i cała w obrysie zdecydowanych kresek [...] No, ale się wyrwała w kierunku emancypacji i kolorowych miesięczników.

(Kołodziejczyk 2018: 206)

Ta metamorfoza jednak jest powierzchowna i to właśnie stwierdzenie „teraz popatrzcie na to...” sugeruje tak przyjrzenie się postaci, jak i konieczność wzięcia w nawias jej „wyrwania się” w stronę nowej tożsamości. Za chwilę bowiem czytelnik otrzymuje projekcję stanu psychicznego bohaterki. Z jednej strony, Ilona/Wiktoria otrzymuje od otoczenia sygnały, że oto jest pełnowartościową jednostką, dzięki czemu pielęgnuje w sobie poczucie wyższości, z drugiej jednak — nieustannie je traci:

Gdyby tak jeszcze sama była przekonana o własnej wyjątkowości, byłoby lżej. Ale już się wewnętrznie wydygała, cofnęła w progresie do siusiumajtki, która topi się w jeziorze Kalwa.

(Kołodziejczyk 2018: 209)

Tożsamość Ilony/Wiktorii jest więc niejako rozerwana pomiędzy walką między tym, co dane od środowiska, które ją ukształtowało, a tym, co wykreowane przez nią samą. Tę szarpaninę, rozgrywającą się pomiędzy pozorem a afektem, można określić mianem koła, po orbicie którego krąży Ilona/Wiktoria. Z jednej strony bowiem bohatera chce wierzyć, że ma kontrolę nad swoją tożsamością, z drugiej — sytuacje skrajne z tej równowagi ją wyprowadzają i zmuszają do powtarzania schematów reakcji, na przykład słownych:

- Goń buta, bo bmusiała krzyknąć po policjanta! Jezu, znowu wylazła z niej stara - to takie skracanie słów, gdy nerwy, ta taka religijność od ręki, o Jadwigo Andegaweńsko i Matko Jedyna! Szczerze? — genetycznie cała stara. 
To szarpanina, z której trudno się wyrwać, a którą podkreśla wielogłosowość ją otaczająca, jest ilustracją tej specyficznej walki pomiędzy tożsamością daną a wykreowaną, pomiędzy słowem „własnym” a „cudzym”. Ilustruje to zjawisko rozdział 39. pod tytułem Dzień. Wnętrze. Sprawy rodzinnie. Stylizowany na tekst dramatyczny fragment wskazuje bowiem na to, że tożsamość dana przez pierwotne środowisko, jakim jest rodzina, jest momentami silniejsza niż tożsamość wykreowana i to właśnie ta pierwsza tożsamość „steruje” reakcjami. Tak więc, najpierw przemawia wyniosła Wiktoria, która siostrom opowiada o urokach miejskiego życia; następnie interakcje z rodzeństwem wyrywają z wnętrza Wiktorii - Ilonę, ciągle niepewną, szukającą poklasku, lecz jednak ciągle ukrytą, niejako zdominowaną; a innym jeszcze razem - Ilona dominuje nad Wiktorią wskutek wyliczenia przez ojca jej życiowych (jego zdaniem) niepowodzeń. Niespodziewane sytuacje najczęściej zmuszają jednostkę do reakcji zaprogramowanych w ich psychice. Nową, często powierzchowną tożsamość łatwo jest bowiem wykreować, trudniej jednak zmienić zaprogramowane reakcje.

Warto też zauważyć, że narracja Prymitywa oscyluje wokół postaci, które są członkami tej samej grupy społecznej, dzielą tę samą wiedzę, mają podobny jej zasób, co im pozwala na to, by prowadzić tzw. dialog niewypowiedziany. Każde zaś odejście od paradygmatu tej małej społeczności, jaką w wypadku tejże powieści jest (peryferyjna) Warszawa, grozi wykluczeniem, nierozumieniem owej uzupełniającej się wielogłosowości. Ten specyficzny niewypowiedziany dialog rozgrywa się pomiędzy niemal wszystkimi bohaterami, uwikłanymi w kulturę życia miejsca, w którym przebywają. Wystarczy słowo-klucz, czy też wytrych, albo gest, mrugnięcie okiem, porozumiewawczy uśmiech, by osiągnąć porozumienie:

$\mathrm{Na}$ rowerach jedzie z dala dwóch młodych, patrzą się, a tu takie cudo na przystanku, chowają rowery za przystanek, a chociaż i tak by ich nikt nie ukradł za wygląd, spinają rowery kłódą; i tak stoją od frontu i coś cicho do siebie szu-szu-szu, nic nie słychać, o czym, i czy w dobrej intencji. Tylko widać, że się cieszą z widoku Ilony, wręcz mają rozpuk.

— Nie ma śmiechu — mówi jeden do drugiego i się śmieją. — Lilia Melina - mówi drugi i się śmieją. — No-no - mówi drugi ponownie — nadchodzący ideał. — I w śmiech.

(Kołodziejczyk 2018: 218)

W tym fragmencie nicią porozumienia są szepty i „zaklęcia”, które chłopcy wypowiadają między sobą. Innym sposobem są porozumiewawcze gesty, które dla członków wspólnoty stają się utajonymi komunikatami:

Po wszystkim papuga mówi Januszowi, że na niego patrzą. - A kto? - pyta się Cygan. - Oni - mówi ten zdolny papuga i zatacza ręką okrąg w powietrzu oraz unosi brew, znacząco wysuwa czubek języka, chrząka, maca się po uchu, strzepuje nieistniejący paproszek z rękawa, rzuca na chodnik kiepa i dłuuugo go depcze ręcznie robionym butem, a patrzy się w oczy, czy Bombaj na pewno wszystko kuma. 
Wyraźniej ten niewypowiedziany dialog uwidacznia się w dynamicznej narracji stylizowanej na wielogłos:

W poprawczaku siedział w Studzieńcu. Mieli tam rozmowy w stylu: za co? Za cichy chód po ulicy. Jesteś człowiekiem? Spytaj się ludzi. I tym podobnie, zdawkowo i bacznie, mówił także mgr: wpada się kiedyś do fryzjera na Kawęczyńskiej koło pętli tramwajów, późno w noc i co widać? Jak raz fryzjer się do baby zabiera

na ostro $[\ldots]$.

(Kołodziejczyk 2018: 167)

Postaci czasem mówią więc indywidualnie — prezentując swój punkt widzenia, innym razem chóralnie zgadzają się ze sobą:

Nagle mimochodem słyszy się w masowym przekazie na imprezie u Beznadziejczuka, że przejmuje nas wszystkich Partia. Nikogo to nic początkowo nie zaprząta, bo jak to się mówi przy każdej zmianie panów; żeby tylko psów po rękach nie gryźli $[\ldots]$.

(Kołodziejczyk 2018: 28)

Zjawisko orkiestracji, polegające na zgodnym i niemal jednoczesnym przemawianiu bohaterów, potęgują czasowniki w formach nieokreślających osoby, np.: styszy się, mówi się oraz zaimek osobowy nas. Wypowiada się więc nie indywiduum, ale kolektyw połączony wspólnotowym porozumieniem. Wydaje się zatem, że powieść Kołodziejczyka to nie tylko demaskowanie sytuacji społeczno-politycznej Polski, lecz także ilustracja wędrówki słowa, nawarstwiania się głosów oraz wielogłosowa interpretacja rzeczywistości, w której narrator zachęca do ostrożności i nieufności wobec tego, co w języku dzieła dane. Prymityw bazuje bowiem na „już przeżytym”, a tym samym „już wypowiedzianym” — déjà dit. Jednocześnie ów narrator nie wartościuje, nie podpowiada i nie faworyzuje, bo uczy czujności. Prymityw to zatem swoista replika tego, co już zaistniało, swoista polemika między tym, co charakterystyczne dla swojego, a tym, co poza owo swoje wybiega. Kołodziejczyk przybierając taką formę wyrazu, zdaje się wszak projektować realne paradygmaty komunikacyjne, w ramach których nie może być mowy o tendencyjności, ale raczej — o wielogłosowości. Słowa bowiem współistnieją, wzajemnie się uzupełniają albo wykluczają, a prawdę sytuują gdzieś „pomiędzy”.

Na koniec wypada jeszcze zauważyć, że powieść Kołodziejczyka to nie jedyny tego typu projekt najnowszej powieści polifonicznej. Podobną praktykę zaobserwować można w powieści Czarne Stońce, w której autor — Jakub Żulczyk — wzorem Kołodziejczyka wybiera formę wielogłosowej narracji celem przeprowadzenia czytelnika przez kształtujące naszą codzienność „cudze słowa”. Teoria wielogłosowości okazuje się tym samym narzędziem ko- 
niecznym do tego, by zrozumieć związek literatury z rzeczywistością, a raczej związek kreacji artystycznej — językowej — ze sposobami negocjowania tożsamości w dynamicznie zmieniającym się świecie.

\section{MARTYNA UJMA}

(iD) https://orcid.org/0000-0002-7896-9941

Doktorantka literaturoznawstwa w Instytucie Literaturoznawstwa Uniwersytetu Humanistyczno-

-Przyrodniczego im. Jana Długosza w Częstochowie oraz lektor języka polskiego jako języka obcego. Przygotowuje rozprawę doktorską W stronę literacko-filozoficznej koinè. Studium o pismach Karola Libelta pod kierunkiem naukowym dra hab. Artura Żywiotka, prof. UJD.

Autorka artykułów naukowych z zakresu teorii literatury, związków literatury i filozofii oraz

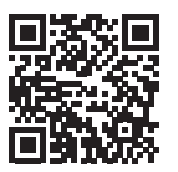
literatury najnowszej. Publikowala na łamach „Zagadnień Rodzajów Literackich”, ,Tematów i Kontekstów”, „Rocznika Komparatystycznego", ,Studia Poetica” i innych. Zainteresowania naukowe: dziewiętnastowieczna literatura i filozofia, literatura najnowsza, teoria literatury, a ostatnio również glottodydaktyka polonistyczna.

Kontakt: martyna-lenart21@wp.pl 


\section{Bibliografia}

Bachtin Michaił (1970), Problemy poetyki Dostojewskiego, przeł. N. Modzelewska, PIW, Warszawa.

Bhabha Homi (1990), The Third Space. Interview with Homi Bhabha [w:] Identity: Community, Culture, Difference, red. Rutherford J., Lawrence \& Wishart, London.

- (1994), The Location of Culture, Routledge, London.

Boski Paweł (2010), Kulturowe ramy zachowań spotecznych. Podręcznik psychologii międzykulturowej, Wydawnictwo Naukowe PWN, Warszawa.

CALD - [Heteroglossia] Cambridge Advanced Learner's Dictionary \& Thesaurus, dictionary. cambridge.org/pl/dictionary/english/heteroglossia [dostęp: 13.04.2020].

Kołodziejczyk Marcin (2018), Prymityw. Epopeja narodowa, Wielka Litera, Warszawa.

Kramsch Claire (2009), Third Culture and Language Education [w:] Contemporary Applied Linguistics, red. Cook V., Wei L., vol. 1: Language Teaching and Learning, Continuum, London.

Nietzsche Friedrich (1993), O prawdzie i ktamstwie w pozamoralnym sensie [w:] tegoż, Pisma pozostate 1862-1875, przeł. B. Baran, Inter esse, Kraków.

Park-Fuller Linda (1986), Voices: Bakhtin's Heteroglossia and Polyphony, and the Performance of Narrative Literature, „Literature in Performance”, nr 7, s. 1-12.

Rorty Richard (2003), Zmierzch prawdy ostatecznej a narodziny kultury literackiej, thum. A. Szahaj, „Teksty Drugie”, nr 6, s. 113-130.

Żyrek-Horodyska (2019), „Postanowitem się rozlać w sensie formalnym”. O transgatunkowym projekcie reporterskim Marcina Kotodziejczyka, „Media. Biznes. Kultura”, nr 2, s. 23-40. 